\title{
Profits From Buying Losers And Selling Winners In The London Stock Exchange
}

\author{
Antonios Antoniou (E-mail: antonios.antoniou@Durham.ac.ak), University of Durham, UK \\ Emilios C. Galariotis (E-mail: emilios.galariotis@dirham.ac.uk), University of Durham, UK \\ Spyros I. Spyrou (E-mail: sis@hol.gr), Athens University of Economics and Business, Greece
}

\begin{abstract}
DeBondt and Thaler (1985) have challenged the notions of market efficiency and of rational investor behaviour. According to their findings stock portfolios that experience negative returns tend to outperform portfolios that experience positive returns, during the subsequent period. In other words, stock returns may be predictable, and this may be due to excessive investor optimism and pessimism. This paper investigates the existence of such contrarian profits for stocks listed in the London Stock Exchange. The results indicate that contrarian strategies are profitable for UK stocks and more pronounced for extreme market capitalisation stocks. These profits persist even after the sample is adjusted for market frictions, and irrespective of whether raw or risk-adjusted returns are used.
\end{abstract}

\section{Introduction}

DeBondt and Thaler (1985) challenge the notions of market efficiency and of rational investor behaviour by demonstrating that portfolios that experience negative returns tend to outperform ones that experience positive returns, by up to $25 \%$ during the subsequent period. They suggest that the observed predictability is due to negative serial correlation and stems from extreme investor optimism and pessimism.

This paper investigates the existence of such contrarian profits for stocks listed in the London Stock Exchange (LSE henceforth) a leading global equity market. There are three main issues that differentiate this paper from previous UK empirical studies. Firstly, it considers short-term contrarian strategies, since investors tend to have short investment horizons and are unlikely to set up very long-term strategies. Secondly, it considers riskadjustments based on three-factor models rather than adjustments that only consider a single (market) factor. Thirdly, it investigates whether the results are affected by market microstructure biases, such as bid ask bias and infrequent trading.

The paper is organised as follows: in the following two sections we briefly review some of the most important studies in the empirical literature and present the sample data. Next, we test for serial correlation since negative serial correlation can transform winners to losers and losers to winners. In other words, if negative serial correlation is present in the data a strategy that shorts each period past winners and longs each period past losers could be profitable. Finally, we present the contrarian trading strategies and also examine whether the results are due to market microstructure biases.

\section{A Brief Review of the Literature}

In the first study that initiated the debate DeBondt and Thaler $(1985,1987)$ find that US long-term stock returns are predictable. That is, portfolios that experience negative returns tend to outperform portfolios that experience positive return, by up to $25 \%$ during the subsequent period. In following studies on US stocks, Jegadeesh (1990), Jegadesh \& Titman (1995), Lehman (1990) produce results that tend to indicate that this may also be the case for short-term contrarian strategies. A first possible explanation of the effect was put forward by Chan (1988) 
and Ball and Kothari (1989) who argued that this phenomenon is due to risk miss measurement and changes in equilibrium required returns. Zarowin (1990) offers another possible explanation arguing that losers have a tendency to be smaller sized firms than winners, in the US market. Still other authors argue that the explanation lies in market frictions such as bid-ask biases and infrequent trading which are not properly accounted (e.g. Conrad and Kaul, 1993). Lo and MacKinlay (1990) point out that these strategies may be profitable even when the returns of some stocks react faster to information than the returns of other stocks (a lead-lag effect). However, Jegadesh and Titman (1995) find that despite the presence of a size-related lead-lag structure most of contrarian profits are due to firmspecific overreaction.

In empirical studies that involve long-term UK market evidence Poterba and Summers (1988) find negative serial correlation consistent with overreaction, while Dissanaike (1997) employs contrarian strategies adjusted for risk and also finds that past losers outperform past winners. Furthermore, Brouwer et al., (1997) come to similar conclusions, Richards (1997) shows that overreaction is unrelated to risk and anomalies, and Balvers et al., (1999) confirm mean reversion and overreaction. Finally, Baytas and Cakiki (1999) find positive and significant profits for contrarian portfolios, and Clare and Thomas (1995) find long-term evidence that seem to be consistent with overreaction. They argue however that the results are related to the size-effect.

\section{Data}

The paper uses weekly price observations for all stocks listed on the LSE that had at least 260 consecutive observations, between 1984 and 2000. The FTSE100 Price Index is employed as a proxy for the common factor (market portfolio). Returns are continuously compounded, defined as the first difference of the logarithmic price levels, and all data are collected from Datastream International. Table 1 presents statistics on the number of firms available for each year and their market values. For example, the largest number of firms (1645) in a single year are for 1990, while the smallest one is met in 1985 (1164 firms). The smallest market value of a firm is below 0.01 million Sterling for years 1989 through 1996, while the maximum market value is for year 2000 (119,814.1 million sterling). Mean market values range from 255.2 million in 1985 to 1,234.6 million in 2000.

Table 1

Total Number of Firms in the Sample and Market Values per year

\begin{tabular}{rrrrc}
\hline Year & $\begin{array}{c}\text { Min. } \\
\text { Value }\end{array}$ & $\begin{array}{l}\text { Max. } \\
\text { Value }\end{array}$ & $\begin{array}{l}\text { Mean } \\
\text { Value }\end{array}$ & $\begin{array}{c}\text { Total no. } \\
\text { of firms }\end{array}$ \\
\hline $\mathbf{1 9 8 5}$ & 0.03 & 63908.49 & 255.1624 & 1164 \\
$\mathbf{1 9 8 6}$ & 0.03 & 66349.63 & 270.0225 & 1247 \\
$\mathbf{1 9 8 7}$ & 0.04 & 50232.23 & 316.029 & 1351 \\
$\mathbf{1 9 8 8}$ & 0.04 & 37661.02 & 310.5211 & 1460 \\
$\mathbf{1 9 8 9}$ & $<0.01$ & 40510.89 & 310.9541 & 1569 \\
$\mathbf{1 9 9 0}$ & $<0.01$ & 42404.25 & 376.6412 & 1645 \\
$\mathbf{1 9 9 1}$ & $<0.01$ & 34655.77 & 313.3649 & 1607 \\
$\mathbf{1 9 9 2}$ & $<0.01$ & 26962 & 373.1171 & 1542 \\
$\mathbf{1 9 9 3}$ & $<0.01$ & 24963.15 & 455.0192 & 1502 \\
$\mathbf{1 9 9 4}$ & $<0.01$ & 30041.87 & 568.5602 & 1521 \\
$\mathbf{1 9 9 5}$ & $<0.01$ & 28257.65 & 525.9799 & 1559 \\
$\mathbf{1 9 9 6}$ & $<0.01$ & 65188.08 & 640.5103 & 1588 \\
$\mathbf{1 9 9 7}$ & 0.04 & 39147.56 & 640.5264 & 1520 \\
$\mathbf{1 9 9 8}$ & 0.04 & 51451.2 & 795.1016 & 1446 \\
$\mathbf{1 9 9 9}$ & 0.04 & 74902.88 & 882.729 & 1340 \\
$\mathbf{2 0 0 0}$ & 0.35 & 119814.1 & 1234.571 & 1195 \\
\hline
\end{tabular}

Note: Values in million of Sterling. 
For the empirical analysis, stocks are assigned to five sub-samples based on market capitalisation (i.e. smallest, small, medium, large, largest firm sub-samples) as follows: every year all stocks are ranked based on the previous year-end stock market capitalisation and subsequently grouped to five sub-samples that each contain $20 \%$ of firms. The procedure is repeated every year, for a period of sixteen years.

Descriptive return statistics based on closing prices are presented in Table 2. The average weekly return for all stocks is $0.05 \%$ with a standard error of 0.017 , while the highest mean return is that of the smallest stock subsample (0.001). The largest stock sub-sample has the second highest return and the highest standard error (0.020).

Table 2

Descriptive Statistics of Stock Returns

\begin{tabular}{ccccccc}
\hline & All Stocks & $\begin{array}{c}\text { Smallest } \\
\text { Stocks }\end{array}$ & $\begin{array}{c}\text { Small } \\
\text { Stocks }\end{array}$ & $\begin{array}{c}\text { Medium } \\
\text { Stocks }\end{array}$ & Large Stocks & Largest Stocks \\
\hline Mean & 0.00050 & 0.00101 & -0.00003 & -0.00002 & 0.00048 & 0.00089 \\
Standard Error & 0.01662 & 0.01784 & 0.01697 & 0.01697 & 0.01796 & 0.01973 \\
Minimum & -0.16978 & -0.14958 & -0.17176 & -0.16546 & -0.17956 & -0.18397 \\
Maximum & 0.06778 & 0.07827 & 0.08295 & 0.07557 & 0.09478 & 0.10306 \\
Jarque-Berra & 15149.6 & 7048.275 & 12268.07 & 9956.03042 & 11318.997 & 12772.641 \\
\hline
\end{tabular}

\section{Negative Serial Correlation}

An important issue in the examination of the predictability of stock returns and profits from contrarian strategies is the existence of negative serial correlation in stock returns. That is, negative serial correlation can transform winners to losers and losers to winners, in other words, a strategy that shorts each period past winners and longs each period past losers could be profitable. Thus, as a first step in the analysis, this paper investigates whether negative serial correlation is present in the data.

However, since authors have pointed out that how one defines abnormal returns is important for the profitability of contrarian strategies (see for example Chopra et al., 1992), the paper does not only examine simple raw returns but also returns adjusted for risk. We do this in two ways: (a) with a single factor model as is done in most previous studies and (b) with a three-factor model similar to the one suggested by Fama and French (1996).

More specifically, returns are first defined as the residuals $\left(e_{i, t}\right)$ from a market model as follows:

$$
r_{i t}=a_{i}+b_{i} r_{m, t}+e_{i, t}
$$

where $r_{i, t}$ is the raw return of stock $i$ at time $t, r_{m, \mathrm{t}}$ is the return of the market portfolio $(m)$ at time $t$, and $e_{i, t}$ is the market-adjusted return for stock $i$ at time $t$.

Next, returns are defined as the residuals $\left(e_{i, t}\right)$ from a three-factor model as follows:

$$
r_{i t}=a_{i}+b_{m} r_{m, t}+b_{S M B} S M B_{t}+b_{H M L} H M L_{t}+e_{i, t}
$$

In (2) the factor SMB (Small Minus Big) is the difference between the return on a portfolio of small stocks and the return on a portfolio of large stocks. The factor HML (High Minus Low) is the difference between the return on a portfolio of high book-to-market stocks and the return on a portfolio of low book-to-market stocks. The factors are constructed in a similar manner as in Fama and French, 1996. 
The results are presented in Table 3, and suggest that negative serial correlation is present in the data. With raw returns (Panel A) 453 of the sample firms exhibit negative $1^{\text {st }}$ order serial correlation. When market risk is considered (Panel B), 643 firms exhibit $1^{\text {st }}$ order negative serial correlation, while when returns are adjusted for factors similar to the FF ones, 739 firms exhibit $1^{\text {st }}$ order serial correlation. Put simply, in the last case more than half of the firms in the sample are negatively serially correlated in the $1^{\text {st }}$ order, and this could indicate that past losers are less risky than past winners. In order to examine whether firms that trade infrequently affect the above results we also test for serial correlation in the data after excluding all stocks that trade infrequently. The results are similar to the results presented in Table 3, and are not reported here (but are available upon request). To summarise the results thus far, negative correlation appears present in UK stock returns even after adjusting for various risk factors, in line with long term evidence by Balvers et al., (1999), and Poterba and Summers (1988).

Table 3

Serial Correlation \& Significance (All Firms)

\begin{tabular}{|c|c|c|c|c|}
\hline Order & $1^{\text {st }}$ & $2^{\text {nd }}$ & $3^{\text {rd }}$ & $4^{\text {th }}$ \\
\hline \multicolumn{5}{|c|}{ Panel A: Raw Returns } \\
\hline Number of Stocks & 453 & 621 & 918 & 980 \\
\hline $5 \%$ & $119 *$ & $219 *$ & $424 *$ & $491 *$ \\
\hline \multicolumn{5}{|c|}{ Panel B: Risk-Adjusted Returns } \\
\hline Number of Stocks & 643 & 813 & 1018 & 977 \\
\hline $5 \%$ & $200 *$ & $298 *$ & $435 *$ & $430 *$ \\
\hline \multicolumn{5}{|c|}{ Panel C: Three-factor adjusted Returns } \\
\hline Number of Stocks & 739 & 962 & 1144 & 1042 \\
\hline $5 \%$ & $239 *$ & $348 *$ & $480 *$ & $407^{*}$ \\
\hline
\end{tabular}

\section{The Trading Strategy}

As shown above stock returns in the LSE exhibit negative serial correlation. This could potentially create profits for a trading strategy that buys past losers and sells past winners. The trading strategy employed in this paper is a standard short-term contrarian strategy, i.e. it consists of a portfolio that every period is short in the previous period's winners and long in the previous period's losers. The strategy is also employed in previous studies such as Jegadeesh and Titman (1995), Lo and Mackinley (1990), among others. More specifically, the zero-investment portfolios are re-balanced every week, and the profits $\pi_{t}$, are estimated as:

$$
\pi_{t}=-\frac{1}{N} \sum_{i=1}^{N}\left(r_{i, t-1}-\bar{r}_{t-1}\right) r_{i, t}
$$

where, $\bar{r}_{t-1}$ is the lagged return on an equally weighted portfolio that contains all stocks, $r_{i, t-1}$ is the return on stock $i$ at time $t-1$, and $N$ is the number of stocks in the sample.

However, as discussed above, many authors have argued that contrarian profits may be due to biases such as bid-ask biases or infrequent trading. In order to examine whether any observed profits are due to market frictions we also recalculate contrarian profits employing bid-to-bid prices rather than closing prices, and also we recalculate profits after excluding infrequently trading firms. The results are reported in Table 4 for all size sub-samples and the full sample. In Panel A, we report the average contrarian profit for all sub-samples when closing prices are used to compute returns. In Panel B, we report profits when bid-to-bid prices are employed, while in Panel C we report 
profits when infrequently trading firms are excluded. Panel D and E report profits for risk adjusted returns when infrequently trading firms are excluded. Risk adjustment takes place by means of a single factor model (Panel D) and a three-factor model (Panel E), as discussed above.

As can be seen from Table 4 (Panel A) contrarian profits are statistically significant for the smallest, large, and largest sub-sample. For example, the average weekly contrarian profit $\left(\pi \times 10^{3}\right)$ is 0.156 and 0.338 for the smallest and the largest sub-sample respectively. Note that, Jegadeesh and Titman, for the US market find higher average weekly contrarian profits and also while in the US contrarian profits decline as one moves from small to large stocks, the opposite seems to happen in the LSE. The profits with the bid-to-bid prices (Panel B) appear lower, thus, it appears that a bid-ask bias may affect results. For example, the average weekly profit for the all stock-group is 0.029 from 0.076 and statistically insignificant. When infrequently trading firms are excluded (Panel C) average weekly profits also appear lower. For example, the average weekly contrarian profit for largest stocks is now 0.101 from 0.338 in Panel A, while for smallest stocks it is 0.081 from 0.156 . The results so far seem to suggest that part of the profits may be due to infrequent trading and also that contrarian strategies are profitable only for the two extreme size sub-samples.

The average weekly contrarian profits that are obtained from risk adjusted returns (Panels E and D) exhibit a different picture. Firstly, profits are positive and statistically and significant at the 5\% level for nearly all subsamples. Secondly profits decline as one moves from smallest to large stock sub-samples (similar to the results of previous studies for the US market.

Table 4

Contrarian Profits $(\pi)$

\begin{tabular}{|c|c|c|c|c|c|c|}
\hline & $\begin{array}{c}\text { All } \\
\text { Stocks } \\
\end{array}$ & $\begin{array}{c}\text { Smallest } \\
\text { Stocks }\end{array}$ & $\begin{array}{c}\text { Small } \\
\text { Stocks }\end{array}$ & $\begin{array}{c}\text { Medium } \\
\text { Stocks }\end{array}$ & $\begin{array}{l}\text { Large } \\
\text { Stocks } \\
\end{array}$ & $\begin{array}{c}\text { Largest } \\
\text { Stocks }\end{array}$ \\
\hline \multicolumn{7}{|c|}{ Panel A: Closing prices (all stocks) } \\
\hline$\pi \times 10^{3}$ & $\begin{array}{l}0.07625 \\
(2.320)^{*}\end{array}$ & $\begin{array}{l}0.15630 \\
(2.753)^{*}\end{array}$ & $\begin{array}{c}-0.01585 \\
(-0.749)\end{array}$ & $\begin{array}{c}0.03611 \\
(0.426)\end{array}$ & $\begin{array}{l}-0.06839 \\
(-4.480)^{*}\end{array}$ & $\begin{array}{c}0.33848 \\
(2.495)^{*}\end{array}$ \\
\hline \multicolumn{7}{|c|}{ Panel B: Bid-to-Bid Prices } \\
\hline$\pi \times 10^{3}$ & $\begin{array}{c}0.02886 \\
(1.046)\end{array}$ & $\begin{array}{c}0.05741 \\
(1.032)\end{array}$ & $\begin{array}{c}0.07459 \\
(0.613)\end{array}$ & $\begin{array}{l}-0.09078 \\
(-5.255)^{*}\end{array}$ & $\begin{array}{l}-0.04829 \\
(-3.323)^{*}\end{array}$ & $\begin{array}{l}0.09572 \\
(5.556)^{*}\end{array}$ \\
\hline \multicolumn{7}{|c|}{ Panel C: Excluding Stocks that Trade Infrequently } \\
\hline$\pi \times 10^{3}$ & $\begin{array}{c}-0.00127 \\
(-0.101)\end{array}$ & $\begin{array}{c}0.08120 \\
(1.953)^{* *}\end{array}$ & $\begin{array}{c}-0.03391 \\
(-1.528)\end{array}$ & $\begin{array}{l}-0.04713 \\
(-2.143)^{*}\end{array}$ & $\begin{array}{l}-0.06867 \\
(-5.138)^{*}\end{array}$ & $\begin{array}{l}0.10132 \\
(7.056)^{*}\end{array}$ \\
\hline \multicolumn{7}{|c|}{ Panel D: Single-Factor Risk-Adjusted Returns (Frequent Trading Stocks) } \\
\hline$\pi \times 10^{3}$ & $\begin{array}{c}0.00243 \\
(0.197)\end{array}$ & $\begin{array}{l}0.21672 \\
(5.185)^{*}\end{array}$ & $\begin{array}{c}0.060575 \\
(2.995)^{*}\end{array}$ & $\begin{array}{c}0.03346 \\
(1.703)^{* *}\end{array}$ & $\begin{array}{c}-0.00404 \\
(-0.263)\end{array}$ & $\begin{array}{l}0.11950 \\
(8.537)^{*}\end{array}$ \\
\hline \multicolumn{7}{|c|}{ Panel E: Three-factor Risk-Adjusted Returns (Frequent Trading Stocks) } \\
\hline$\pi \times 10^{3}$ & $\begin{array}{c}0.01777 \\
(1.647)^{* *}\end{array}$ & $\begin{array}{l}0.25554 \\
(6.097)^{*}\end{array}$ & $\begin{array}{l}0.09693 \\
(4.874)^{*}\end{array}$ & $\begin{array}{c}0.058466 \\
(3.109)^{*}\end{array}$ & $\begin{array}{c}0.028521 \\
(1.997)^{*}\end{array}$ & $\begin{array}{c}0.12992 \\
(10.369)^{*}\end{array}$ \\
\hline
\end{tabular}


In order to examine the economic significance of these contrarian profits, the contrarian profit per Sterling long $(\Psi)$ are estimated as follows as suggested by Bacmann and Dubois 1998. More specifically the contrarian profit per Sterling long $(\Psi)$ is:

$$
\psi_{t, k}=\frac{\sum_{1=1}^{N_{t-1}} w_{i, t}^{+} r_{i, t}}{\sum_{1=1}^{N_{t-1}} w_{i, t}^{+}}
$$

where $w_{i, t}^{+}=-\frac{1}{N_{t-1}}\left(r_{i, t-1}-r_{m, t-1}\right)$ if $r_{i, t-1}<r_{m, t-1}$ or 0 otherwise. $\Psi$ is defined to provide profits only when each asset's lagged returns are lower than the lagged average returns of all stocks in the sample, in which case the position on that asset next period would be long. Obtaining a weighted average of returns $(\Psi)$ results to returns per Sterling long. The results for contrarian profits per Sterling long are reported in Table 5 (organised exactly as Table 4) and suggest that contrarian profits are positive and economically significant for most sub-samples only when returns are adjusted for risk. For example, when a three-factor model is used to adjust for risk the contrarian profit per Euro long for the smallest stock sub-sample is 0.00567 with a significant $t$-statistic of 5.094. The contrarian profit per Euro long for the largest stock sub-sample is 0.00368 with a significant $t$-statistic of 7.938 .

Table 5

Contrarian Profits Per Euro Long ( $\Psi$ )

\begin{tabular}{|c|c|c|c|c|c|c|}
\hline & $\begin{array}{c}\text { All } \\
\text { Stocks } \\
\end{array}$ & $\begin{array}{c}\text { Smallest } \\
\text { Stocks }\end{array}$ & Small Stocks & $\begin{array}{c}\text { Medium } \\
\text { Stocks } \\
\end{array}$ & $\begin{array}{l}\text { Large } \\
\text { Stocks } \\
\end{array}$ & $\begin{array}{c}\text { Largest } \\
\text { Stocks } \\
\end{array}$ \\
\hline \multicolumn{7}{|c|}{ Panel A: Closing prices (all stocks) } \\
\hline$\Psi$ & $\begin{array}{c}0.00221 \\
(1.561)\end{array}$ & $\begin{array}{l}0.00704 \\
(3.366)^{*}\end{array}$ & $\begin{array}{c}-0.00014 \\
(-0.121)\end{array}$ & $\begin{array}{l}-0.00294 \\
(-2.690)^{*}\end{array}$ & $\begin{array}{l}-0.00285 \\
(-2.675)^{*}\end{array}$ & $\begin{array}{c}0.00487 \\
(1.429)\end{array}$ \\
\hline \multicolumn{7}{|c|}{ Panel B: Bid-to-Bid Prices } \\
\hline$\Psi$ & $\begin{array}{c}0.00201 \\
(0.908)\end{array}$ & $\begin{array}{c}0.00168 \\
(1.063)\end{array}$ & $\begin{array}{c}0.00394 \\
(0.699)\end{array}$ & $\begin{array}{l}-0.00474 \\
(-4.032)^{*}\end{array}$ & $\begin{array}{c}-0.00213 \\
(-1.860)^{* *}\end{array}$ & $\begin{array}{l}0.00357 \\
(3.035)^{*}\end{array}$ \\
\hline \multicolumn{7}{|c|}{ Panel C: Excluding Stocks that Trade Infrequently } \\
\hline$\Psi$ & $\begin{array}{c}0.00052 \\
(0.574)\end{array}$ & $\begin{array}{c}0.003325 \\
(2.265)^{*}\end{array}$ & $\begin{array}{c}-0.00117 \\
(-0.977)\end{array}$ & $\begin{array}{l}-0.00420 \\
(-3.502)^{*}\end{array}$ & $\begin{array}{l}-0.00210 \\
(-2.231)^{*}\end{array}$ & $\begin{array}{l}0.00315 \\
(3.656)^{*}\end{array}$ \\
\hline \multicolumn{7}{|c|}{ Panel D: Single-Factor Risk-Adjusted Returns (Frequent Trading Stocks) } \\
\hline$\Psi$ & $\begin{array}{c}-0.00029 \\
(-0.448)\end{array}$ & $\begin{array}{l}0.00544 \\
(4.454)^{*}\end{array}$ & $\begin{array}{l}0.00289 \\
(3.169)^{*}\end{array}$ & $\begin{array}{c}0.00015 \\
(0.153)\end{array}$ & $\begin{array}{c}0.00005 \\
(0.084)\end{array}$ & $\begin{array}{l}0.00332 \\
(6.447)^{*}\end{array}$ \\
\hline \multicolumn{7}{|c|}{ Panel E: Three-factor Risk-Adjusted Returns (Frequent Trading Stocks) } \\
\hline$\Psi$ & $\begin{array}{c}0.00009 \\
(0.151)\end{array}$ & $\begin{array}{l}0.00567 \\
(5.094)^{*}\end{array}$ & $\begin{array}{l}0.00381 \\
(4.517)^{*}\end{array}$ & $\begin{array}{c}0.00086 \\
(1.007)\end{array}$ & $\begin{array}{c}0.00084 \\
(1.369)\end{array}$ & $\begin{array}{l}0.00368 \\
(7.938)^{*}\end{array}$ \\
\hline
\end{tabular}


To summarise thus far, contrarian strategies produce statistically $(\pi)$ and economically $(\psi)$ significant profits in the LSE, irrespective of how stock returns are defined. In addition, the two most "profitable" sub-samples appear to be the two extreme size sub-samples. Furthermore, profits decline as one moves from the smallest stock sub-sample to larger stock sub-samples. The paper's findings so far on short-term profitability are in line in most aspects with studies for the US market, and consistent with long-term findings for the UK stock market (e.g. Dissanaike, 1997, Brouwer et al., 1997, etc).

\section{Concluding Remarks}

This paper investigates the existence of short-term contrarian profits for stocks listed in the LSE. The main result that emerges from the empirical analysis is that contrarian strategies produce statistically and economically significant profits that are not explained by infrequent trading, bid-ask biases, and risk. Furthermore, profits are more pronounced for extreme market capitalization stocks (smallest - largest), and LSE investors could thus employ contrarian strategies for such stocks.

The results presented in the paper seem to suggest that past prices predict future returns, implying that the market is not efficient with respect to historical information. This is consistent with previous results for the UK market on long-term price reversals. Furthermore, it is demonstrated that short-term contrarian profits are not specific for US data.

With respect to market participants, the facts show that contrarian strategies in the LSE are also profitable for short-term horizons and more importantly, profits are not due to taking on excess risk directly or indirectly, since profits exist for risk adjusted returns of even large and more liquid stocks.

A question that arises at this point is on the factors that drive these profits; i.e. are they firm specific or market wide factors, and if both of these sets of factors contribute, to what extent does each one do. It would thus be very interesting to examine this issue further. This however, is the work of another working paper by the Antoniou, Galariotis and Spyrou (2003).

\section{References}

1. Antoniou, A., Galariotis E.C., Spyrou, S.I., 2003. "Short-term contrarian strategies in the London Stock Exchange: are they profitable? Which factors affect them?”, Working paper, Centre for Empirical Research in Finance, Durham Business School.

2. Bacmann, J.F., Dubois, M., 1998. "Contrarian strategies and cross-autocorrelations in stock returns: evidence from France", Social Science Research Network Electronic Library, \& European Financial Management Association 1998 Meeting.

3. Ball, R., Kothari, S.P., 1989. "Non-stationary expected returns: implications for tests of markets efficiency and serial correlation in returns", Journal of Financial Economics, 25, 51-74.

4. Balvers, R., Wu Y., Gilliland, E., 1999. "Mean reversion across national stock markets and parametric contrarian investment strategies", Journal of Finance, 55, 745-772.

5. Baytas, A., Cakici, N., 1999. "Do markets overreact? International evidence", Journal of Banking and Finance, 23, 1121-1144.

6. Brouwer, I., Van Der Put, J., Veld, C., 1997. "Contrarian investment strategies in a European context", Journal of Business Finance \& Accounting, 24, 306-386.

7. Chan, C., 1988. "On the contrarian investment strategy", Journal of Business, 61, 147-164.

8. Chopra, N., Lakonishok, J., Ritter, J., 1992. "Do stocks overreact?”, Journal of Financial Economics, 31, 235-268.

9. Chordia, T., Shivakumar, R., 2002. "Momentum, Business Cycle, and Time varying expected returns", Journal of Finance, 57, 985-1019. 
10. Clare, A., Thomas, S., 1995. "The overreaction hypothesis and the UK stock returns", Journal of Business Finance and Accounting, 22, 961-973.

11. Conrad, J., Kaul, G., 1993. "The returns to long term winners and losers: bid-ask biases in computed returns", Journal of Finance, 48, 39-63.

12. Davis, J., Fama, E., French, K., 2000. “Characteristics, covariances, and average returns: 1929-1997”, Journal of Finance, 55, 389-406.

13. De Bondt, W.F.M., Thaler, R.H., 1985. "Does the stock market overreact?", Journal of Finance, 40, 793-805.

14. De Bondt, W.F.M., Thaler, R.H., 1987. "Further evidence on investor overreaction and stock market seasonality", Journal of Finance, 42, 557-581.

15. Dissanaike G.,1997. "Do stock market investors overreact?", Journal of Business Finance \& Accounting, 24, 27-50.

16. Fama, E., French, K.R. 1996. "Multifactor explanations of asset pricing anomalies", Journal of Finance, 52, 55-84.

17. Jegadeesh, N., 1990. "Evidence of predictable behaviour of security returns", Journal of Finance 45, 881-898.

18. Jegadeesh, N., Titman, S., 1995. "Overreaction, delayed reaction, and contrarian profits", Review of Financial Studies, 8, 973-993.

19. Kaul, G., Conrad, J., Gultekin M., 1997. "Profitability of short-term contrarian strategies: implications for market efficiency", Journal of Business \& Economic Statistics, 15, 379-386.

20. Kaul, G., Nimalendran, M., 1990. "Price reversals, bid-ask errors or market overreaction?", Journal of Financial Economics, 28, 67-93.

21. Lehman, B., 1990. "Fads, martingales, and market efficiency", Quarterly Journal of Economics, 35, 401-428.

22. Lo, A.W., MacKinlay, A.C., 1990. "When are contrarian profits due to market overreaction?”, Review of Financial Studies, 3, 175-205.

23. Poterba J., Summers, H.L., 1988. "Mean reversion in stock prices: evidence and implications", Journal of Financial Economics, 22, 27-59.

24. Richards, A., 1997. "Winner-loser reversals in national stock market indices: can they be explained?", Journal of Finance, 53, 2129-2144.

25. Zarowin, P., 1990. "Size, seasonality and stock market overreaction", Journal of Financial and Quantitative Analysis, 25, 113-125. 